\title{
Perancangan Arsitektur Bisnis Pada Industri Aluminium Foil Menggunakan TOGAF
}

\author{
Brahmatia Wicaksono ${ }^{1}$, Johanes Fernandes Andry ${ }^{2}$ \\ Jurusan Sistem Informasi, Fakultas Teknologi dan Desain, Universitas Bunda Mulia ${ }^{1}$ \\ Fakultas Teknologi dan Desain, Universitas Bunda Mulia ${ }^{2}$ \\ Brahmatiawicaksono@gmail.com ${ }^{1}$, jandry@bundamulia.ac.id ${ }^{2}$
}

\begin{tabular}{l}
\hline \hline Article Info \\
\hline History: \\
Dikirim 02 April 2020 \\
Direvisi 29 juni 2020 \\
Diterima 24 Juli 2020 \\
\hline
\end{tabular}

\section{Kata Kunci:}

PT. Bumi Poly Imas Industries Arsitektur Bisnis

TOGAF

Almunium Foil

Blueprint

\begin{abstract}
Abstrak
Teknologi memiliki dampak besar dalam kehidupan manusia, peran teknologi informasi tidak diragukan lagi dalam bidang manufaktur misalnya. PT. Bumi Poly Imas Industries (BPII) merupakan sebuah perusahaan manufaktur yang menghasilkan produk almunium foil dan rotogravure, PT. BPII sudah menerapkan teknologi sistem informasi melalui pemakaian aplikasi yaitu Accurate, Solution dan Payroll yang digunakan pada untuk membantu kinerja dari bagian pergudangan (warehouse), finance, dan penggajian. Namun penerapan tersebut masih belum maksimal dalam membantu proses bisnis dalam perusahaan agar mampu bertahan dalam persaingan bisnis, mempunyai kinerja dari karyawan yang optimal, dan memberikan yang terbaik bagi client. Sehingga diperlukan pengembangan pada teknologi sistem informasi perusahaan tersebut yang selaras dengan bisnis PT. BPII. Pengembangan teknologi berdasarkan rancangan arsitektur bisnis, yang menghasilkan suatu blue print perusahaan. Dan untuk menghasilkan sebuah blueprint tersebut perlu dibantu dengan adanya framework arsitektur, pada penelitian ini menggunakan framework TOGAF (The Open Group Architecture Framework). Pemilihan framework TOGAF untuk digunakan dalam penulisan ini dikarenakan, dengan framework ini dapat membantu menganalisis kebutuhan perusahaan. Selain itu, framework ini memiliki metode yang untuk pengembangan arsitektur bisnis perusahaan. Dengan observasi ke perusahaan dan melakukan wawancara, diperoleh data proses bisnis yang dibutuhkan. Sehingga dari penelitian ini dihasilkan Blue Print Desain Arstitektur dari metode TOGAF yang disesuaikan dengan proses bisnis pada PT. BPII yang diharapkan dapat membantu proses kinerja perusahaan agar semakin efektif dan cepat, mencapai visi dan misi perusahaan.
\end{abstract}

(C) This work is licensed under a Creative Commons Attribution-ShareAlike 4.0 International License.

\section{Koresponden:}

Johanes Fernandes Andry,

Program Studi Sistem Informasi, Fakultas Teknologi dan Desain

Universitas Bunda Mulia,

Jl. Lodan Raya No. 2 Ancol, Jakarta Utara, Indonesia 14430

Email: jandry@bundamulia.ac.id

\section{PENDAHULUAN}

Teknologi menjadi hal yang penting dalam kehidupan. Teknologi bukan tren lagi, tetapi sudah menjadi sesuatu yang umum digunakan oleh berbagai orang di masyarakat dan digunakan di hampir 
setiap aspek kehidupan. Teknologi dapat membantu berbagai hal bekerja lebih baik dan lebih mudah. Jika teknologi digunakan dengan benar, itu bisa meningkat produktivitas dan dapat membuat kualitas hidup yang lebih baik. Berbagai teknologi digunakan untuk menyelesaikan tujuan spesifik dihidup [1].

Teknologi informasi (TI) memiliki dampak lebih dan lebih pada pendapatan perusahaan, membuat perbedaan pada fungsi evolusi mereka. Sistem Informasi kini menjadi investasi massa depan, kelincahan pasar dunia, dan perubahan eksponensial. Ini juga merupakan aset di mana perusahaan dapat mengandalkan untuk mencapai tujuan bisnis [2].

Integrasi teknologi sistem informasi yang tepat akan mendukung rencana dan pengembangan bisnis perusahaan yang nantinya akan memberikan nilai tambah dalam persaingan bisnis [3]. Berdasarkan hal tersebut, dibutuhkan suatu sistem informasi dan teknologi informasi yang dapat digunakan untuk mengelola data dari seluruh proses bisnis yang ada demi mencapai visi dan misi perusahaan. Untuk membangun suatu sistem informasi dan teknologi informasi tersebut, dibutuhkan suatu perancangan arsitektur enterprise yang sesuai dengan kebutuhan bisnis di PT. BPII yang bergerak dalam industri aluminium foil [4]. Arsitektur enterprise merupakan salah satu tool untuk membangun keselarasan strategi bisnis dengan teknologi informasi, dengan melakukan pendekatan sistematis untuk mengelola aset sistem dan informasi serta mengarahkan kebutuhan strategis bisnis dengan perencanaan, tata kelola TI dan manajemen portofolio yang sesuai. Enterprise Arsitektur Framework digunakan untuk mengatur, mendeskripsikan, dan menampilkan seluruh isi dari informasi yang ada dalam perusahaan. Perancangan arsitektur enterprise ini berguna untuk memberikan suatu blue print serta usulan platform kepada PT.BPII [5].

Untuk menghasilkan blueprint perusahaan dalam merancang arsitektur enterprise maka penelitian ini membutuhkan framework arsitektur yang dapat memberikan pendekatan komprehensif untuk merancang, perencanaan, pelaksanaan, dan tata kelola arsitektur informasi perusahaan. Pemilihan Framework yang digunakan dalam penelitian ini untuk diterapkan dalam perancangan EA adalah The Open Group Architecture Framework (TOGAF) karena memberikan metode yang detail tentang bagaimana membangun dan mengelola serta mengimplementasikan arsitektur enterprise yang dipadukan bersama penggunaan sistem informasi yang disebut dengan Architecture Development Method (ADM) [6].

Dalam penelitian ini akan dibahas bagaimana menggunakan The Open Group Architecture Framework (TOGAF) dalam merancang Arsitektur Bisnis Perusahaan sehingga didapatkan rancangan Arsitektur bisnis yang memenuhi kebutuhan proses bisnis yang selaras dengan visi dan misi dari PT. BPII.

\section{Studi Terdahulu}

Penelitian yang dilakukan oleh Geasela dan Andry tahun 2019, didapatkan perkembangan teknologi informasi di Indonesia pada saat ini berpengaruh hingga dunia bisnis, salah satunya yaitu Industri CPO yang merupakan perusahaan terbatas yang didirikan di Indonesia. Industri CPO bergerak di bidang agri bisnis industri dan manufaktur kelapa sawit, kawasan industri CPO sendiri terletak di Pulau Kalimantan Timur. Industri CPO sudah menerapkan penggunaan beberapa aplikasi dalam mendukung proses bisnisnya, selain itu karena teknologi informasi memberikan peluang baru bagi perusahaan. Industri CPO bekerja sama dengan beberapa perusahaan penambangan batubara terbesar di Indonesia dengan manajemen penambangan batubara yang selalu memenuhi persyaratan, itu diakui setiap tahun dari Lingkungan Lembaga. Untuk meningkatkan daya saing perusahaan dibutuhkan arsitektur enterprise untuk membantu membangun atau mendesain informasi teknologi yang akan mengarahkan perusahaan untuk dapat memiliki teknologi informasi yang terintegrasi dengan baik serta dengan didukung dengan framework TOGAF. Dihasilkan sebuah blueprint yang berguna bagi Industri CPO, yang diharapkan dapat membantu perusahaan dalam memproses pengembangan dan merencanakan aplikasi pembantu dan diharapkan untuk merancang ini aplikasi dapat meningkatkan bisnis industri CPO [7]. 


\section{METODE PENELITIAN}

Metode yang akan digunakan pada penelitian ini adalah The Open Group Architecture Framework (TOGAF), adapun tahapan-tahapan penelitian yang di lalui, dapat dilihat pada Gambar 1.

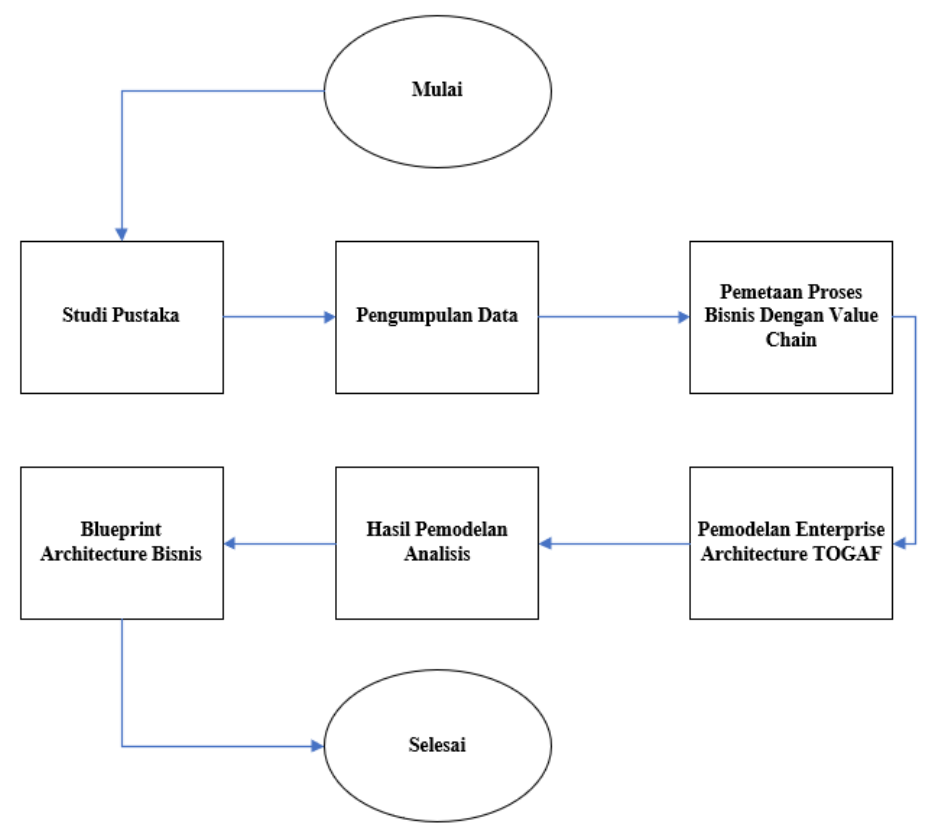

Gambar 1. Tahapan Penelitian [8]

Berdasarakan langkah penelitian pada Gambar 1, maka dapat dijelaskan sebagai berikut ini:

1. Studi literatur: pengumpulan data-data dari pustaka sebagai referensi yang berasal dari jurnal penelitian dan informasi lain yang berkaitan dengan penelitian ini.

2. Pengumpulan data: pengumpulan data proses bisnis perusahaan secara menyeluruh dan dilakukan dengan analisis hasil dari datang ke PT. BPII, bertemu dan melakukan wawancara dengan Pak Hendra selaku purchasing, Ibu Dies selaku HRD, dan Ibu Susi selaku General Manager di perusahaan tersebut

3. Pemetaan Proses Bisnis Dengan Value Chain: Menjelaskan kegiatan utama dan kegiatan pendukung dari proses bisnis di PT. BPII.

4. Perancangan Enterprise Architecture TOGAF: Pada tahap ini akan membahas perancangan dari usulan aplikasi pada penelitian ini menggunakan framework TOGAF sebagai dasar. Tahap ini terdiri dari preliminary phase, architecture vision, business Architecture, information system architecture, serta technology architecture

5. Hasil perancangan dan Analisis: melakukan analisis dengan menyatukan hasil dari pemodelan TOGAF dan ditentukan yang mana akan dibuat proses pengembangannya.

6. Blue Print Architecture Bisnis: membahas mengeneai hasil usulan pengembangan yang telah dianalisis sebelumnya.

\subsection{Teori Relevan}

\subsubsection{Arsitektur Bisnis}

Pada tahapan ke dua dari TOGAF ADM yaitu Arsitektur Bisnis (Business Architecture) [9], secara umum arsitektur bisnis menggambarkan kumpulan aktivitas bisnis, data, dan informasi yang berasal dari lingkungan organisasi baik itu internal maupun eksternal. Arsitektur bisnis merupakan representasi formal serta informasi bagi profesional bisnis organisasi dalam menilai, merubah maupun merancang bisnis [10]. 


\subsubsection{TOGAF}

TOGAF atau yang diketahui dengan sebutan The Open Group Architecture Framework merupakan sebuah framework yang pada awalnya TOGAF digunakan oleh Departemen Pertahanan Amerika namun seiring berjalannya waktu, TOGAF mulai digunakan dalam berbagai bidang seperti industri manufaktur, perbankan dan pendidikan. TOGAF merupakan framework yang detail sebagai tool pendukung yang digunakan untuk mengembangkan arsitektur teknologi informasi pada suatu organisasi. Framework ini menghubungkan konsep yang menggambarkan dunia nyata kepada konsep sistem informasi dan implementasinya.

Dapat disimpulkan bahwa TOGAF merupakan framework yang digunakan untuk enterprise architecture yang menyediakan pendekatan yang digunakan untuk merancang, merencanakan, dan mengimplementasikan arsitektur teknologi perusahaan [6]. TOGAF dapat memberikan metode secara terperinci bagaimana cara nya untuk membangun, mengelola, hingga mengimplementasikan suatu arsitektur enterprise bersama sistem informasi yang disebut dengan Architecture Development Method (ADM). Metode ini menggabungkan elemen dari TOGAF dengan kebutuhan bisnis dan TI organisasi dan digunakan sebagai panduan untuk merencanakan, merancang, mengembangkan, dan mengpenerapan kan arsitektur sistem informasi untuk organisasi [11]. Dalam ADM sendiri memiliki 8 fase utama, diperlihatkan pada Gambar 2. Fase ADM.

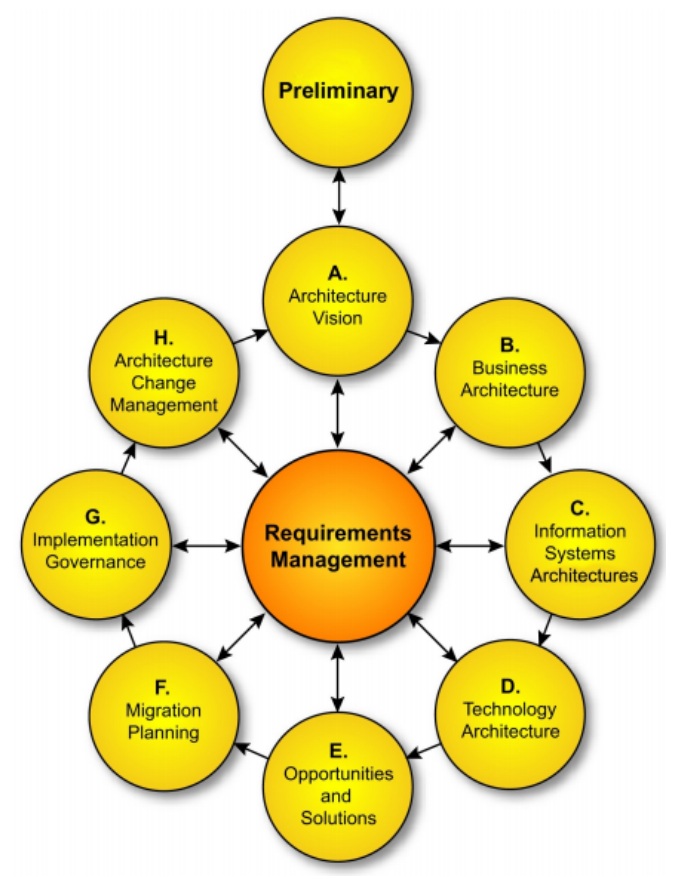

Gambar 2. Fase ADM [11].

a. Preliminary: Fase preliminary mencakup aktivitas untuk meyakinkan pihak yang terlibat dalam penggunaan teknologi sistem dan mendefinisikan prinsip-prinsip arsitektur.

b. Fase A: Visi Arsitektur: Fase ini mencakup visi misi, tujuan bisnis, hingga identifikasi stakeholders.

c. Fase B: Arsitektur Bisnis: Fase ini mencakup pengembangan arsitektur bisnis perusahaan yang berguna dalam mendukung tujuan bisnis.

d. Fase C: Arsitektur Sistem Informasi: Pada fase ini menekankan lebih kepada aktivitas dari arsitektur sistem informasi yang dikembangkan.

e. Fase D: Arsitektur Teknologi: Fase ini mencakup tentang bagian arsitektur data bisni

f. Fase E: Peluang dan Solusi: Pada fase ini akan dievaluasi model yang telah dibangun untuk arsitektur saat ini dan tujuan 
g. Fase F: Perencanaan Migrasi: Fase mencakup tentang bagaimana cara berpindah dari arsitektur saat ini ke Arsitektur target

h. Fase G: Tata Kelola Implementasi: Fase ini mencakup pengawasan terhadap implementasi arsitektur.

i. Fase H: Arsitektur Manajemen Perubahan: Fase ini mencakup tentang menetapkan prosedur untuk mengelola perubahan pada arsitektur baru

\section{HASIL DAN PEMBAHASAN}

\subsection{Analisis Value Chain}

Ditahap ini akan dijelaskan analisis dari kegiatan utama dan kegiatan pendukung dalam proses bisnis di PT. BPII, penjelasan pada Gambar 3. Value Chaiin PT. BPII.

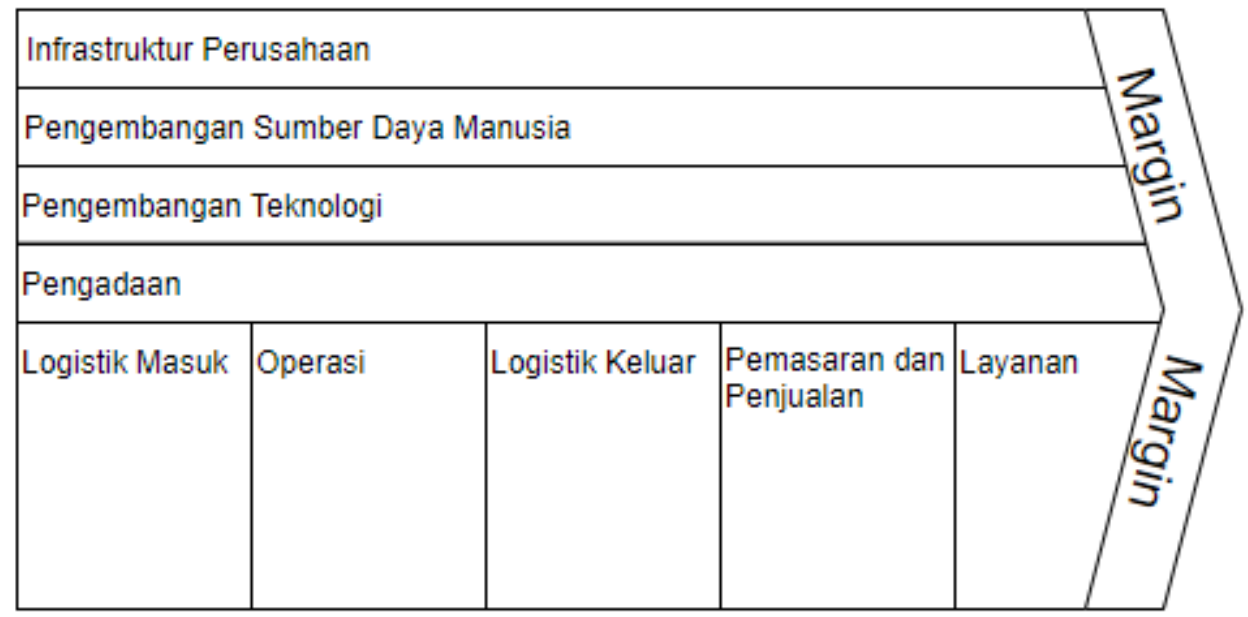

Gambar 3. Value Chain PT. BPII [7].

Aktivitas Utama:

a. Logistik masuk: Bahan baku yang datang ke Gudang akan dilakukan Uji COA (Certificate of Analysis), bahan baku seperti film maupun cat atau pewarna yang dilakukan oleh Quality Control.

b. Operasi: Proses dari awal barang masuk, lalu ke proses produksi pada mesin baik insulation \& rotogravure, dan hasil dari produksi tersebut diuji secara berkala hingga kemudian masuk ke ruangan barang jadi (finish good).

c. Logistik keluar: Barang jadi (almunium foil, packaging rotogravure: choki, aice, ban corsa, archilles, dll) yang ditempatkan di gudang barang jadi dikirim ke klien.

d. Pemasaran dan penjualan: Melihat harga pasar luar negeri, bekerja sama dengan berbagai produk untuk promosi, menambahkan customer baru, mempromosikan keunggulan yang tidak dimiliki oleh banyak kompetitor.

e. Layanan: Teknikal support berupa Quality Control untuk barang jadi maupun barang retur.

\section{Kegiatan Pendukung:}

a. Infrastruktur Perusahaan: Dimulai dari gedung perusahaan, jalan menuju pabrik, mesin" insulation \& rotogravure, gudang, ruang penyimpanan barang jadi yang akan segera dikirim ke client.

b. Pengembangan sumber daya manusia: Setelah melakukan tanda tangan kontrak, karyawan baru akan menjalani training dengan turun langsung ke lapangan. 
c. Pengembangan teknologi: Saat ini masih menggunakan Microsoft Excel, Accurate5 Deluxe, dan Omegasoft Payroll.

d. Pengadaan: Bahan Baku yang digunakan dalam proses produksi (film NYLON, film OPP, PET, SOLVENT, ADH), adapula bahan penolong seperti (baut, silet, majun, ATK).

\subsection{Interaksi Model Enterprise Planning}

Bagian ini mengacu pada fase E dari TOGAF, Opportunities dan Solution. Bagian ini dimaksudkan untuk mengidentifikasi dan memetakan fungsi bisnis di perusahaan. Ada beberapa sistem aplikasi akan di sarankan, seperti: aplikasi inventory, Website E-Commerce, aplikasi pengajuan cuti, aplikasi monitoring sales, DSS Supplier, sistem integrasi data. Kegunaan dari sistem aplikasi yang disarankan, sebagai berikut:

a. Dalam Jangka pendek: terdapat sistem DSS Supplier, sistem membantu PT. BPII dalam menentukan pemasok untuk bahan baku dan bahan penolong yang digunakan dalam proses produksi. Website E-Commerce, mengembangkan Website yang dimiliki PT. BPII menjadi media agar lebih memudahkan cara berinteraksi dengan client.

b. Dalam Jangka Menengah: Website untuk penerimaan karyawan baru yang dapat membantu PT. BPII dalam mencari kandidat karyawan atau pelamar kerja, sedangkan aplikasi inventory yang membantu pihak produksi dalam permintaan barang ke Gudang (warehouse).

c. Dalam Jangka Panjang: aplikasi monitoring sales yang berguna untuk memantau pekerjaan sekaligus lokasi dari sales dan aplikasi pengajuan cuti yang membuat pengajuan cuti oleh karyawan menjadi semakin efisien.

Pemilihan aplikasi-aplikasi tersebut berdasarkan kebutuhan perusahaan akan teknologi informasi yang belum terpenuhi dalam membantu menjalani aktivitas bisnis di PT. BPII yang dilihat dari value chain, diharapkan dengan saran yang diberikan dapat membantu dalam proses kerja agar semakin efisien dan efektif. Berikut akan diberikan sebuah gambar interaksi dari model enterprise planning, bisa dilihat pada Tabel 1. Interaksi Model Enterprise Planning

Tabel 1. Interaksi Model Enterprise Planning

\begin{tabular}{ccc}
\hline Rencana & Aplikasi 1 & Aplikasi 2 \\
\hline Jangka Pendek & DSS Produsen & Website E-Commerce \\
Jangka Menengah & Website untuk penerimaan & Aplikasi Inventory \\
karyawan baru & \\
Jangka Penjang & Aplikasi Monitoring Sales & Aplikasi Pengajuan Cuti \\
\hline
\end{tabular}

\subsection{GAP Arsitektur Bisnis}

Membahas tentang arsitektur bisnis saat ini, menjelaskan jenis TI apa yang digunakan di industri saat ini dan seberapa besar pengaruhnya di industri. Arsitektur bisnis target menjelaskan perencanaan TI dan TI mana yang harus diimplementasikan di masa depan. Analisis kesenjangan ini dimaksudkan untuk menganalisis kondisi saat ini di industri dan membangun rencana arsitektur bisnis untuk diimplementasikan di masa depan. 


\begin{tabular}{|c|c|c|c|c|c|c|}
\hline \multirow[b]{2}{*}{ Future } & \multicolumn{5}{|c|}{ EXISTING } & \multirow[b]{2}{*}{ ADD } \\
\hline & $\begin{array}{l}\text { Accurate5 } \\
\text { Deluxe }\end{array}$ & $\begin{array}{l}\text { Omegasoft } \\
\text { Payroll }\end{array}$ & Solution & $\begin{array}{l}\text { Form } \\
\text { Pengajuan } \\
\text { Cuti }\end{array}$ & $\begin{array}{l}\text { Form } \\
\text { Permintaan } \\
\text { Barang } \\
\end{array}$ & \\
\hline \multicolumn{7}{|l|}{$\begin{array}{l}\text { Accurate5 } \\
\text { Deluxe }\end{array}$} \\
\hline \multicolumn{7}{|l|}{$\begin{array}{l}\text { Omegasoft } \\
\text { Payroll }\end{array}$} \\
\hline \multicolumn{7}{|l|}{ Solution } \\
\hline \multicolumn{7}{|l|}{$\begin{array}{l}\text { Form } \\
\text { Pengajuan } \\
\text { Cuti }\end{array}$} \\
\hline \multicolumn{7}{|c|}{$\begin{array}{l}\text { Form } \\
\text { Permintaan } \\
\text { Barang }\end{array}$} \\
\hline \multicolumn{7}{|c|}{ DSS Produsen } \\
\hline \multicolumn{7}{|l|}{$\begin{array}{l}\text { Website E- } \\
\text { Commerce }\end{array}$} \\
\hline \multicolumn{7}{|c|}{$\begin{array}{l}\text { Website Untuk } \\
\text { Penerimaan } \\
\text { Karyawan } \\
\text { Baru } \\
\end{array}$} \\
\hline \multicolumn{7}{|c|}{$\begin{array}{l}\text { Aplikasi } \\
\text { Inventory }\end{array}$} \\
\hline \multicolumn{7}{|l|}{$\begin{array}{l}\text { Aplikasi } \\
\text { Monitoring } \\
\text { Sales }\end{array}$} \\
\hline $\begin{array}{l}\text { Aplikasi } \\
\text { Pengajuan } \\
\text { Cuti }\end{array}$ & & & & & & \\
\hline
\end{tabular}

Gambar 4. GAP Arsitektur Bisnis

Keterangan gambar :

- Retain (Dipertahankan)

- Replace (Digantikan)

- $\quad$ Add (Ditambahkan)

Penjelasan tentang GAP Arsitektur Bisnis pada Gambar 4, ada aplikasi yang sudah digunakan seperti: Accurate5 Deluxe, OmegaSoft Payroll, Solution tetap digunakan (dipertahankan). Lalu, ada pengisian form pengajuan cuti dan permintaan barang yang masih dilakukan secara manual akan digantikan (Replace). Terakhir, ada yang akan ditambahkan ( $A d d$ ) yakni: DSS Produsen, Website E-Commerce, Website untuk penerimaan karyawan baru, Aplikasi inventory, Aplikasi Monitoring Sales, dan Aplikasi Pengajuan Cuti.

\subsection{Desain Arsitektur Bisnis}

Dibagian ini dibahas desain arsitektur bisnis ini, yang mengarah pada fase B dari TOGAF, Arsitektur Bisnis. Berikut ini adalah desain arsitektur bisnis yang berjalan saat ini pada PT. BPII: 


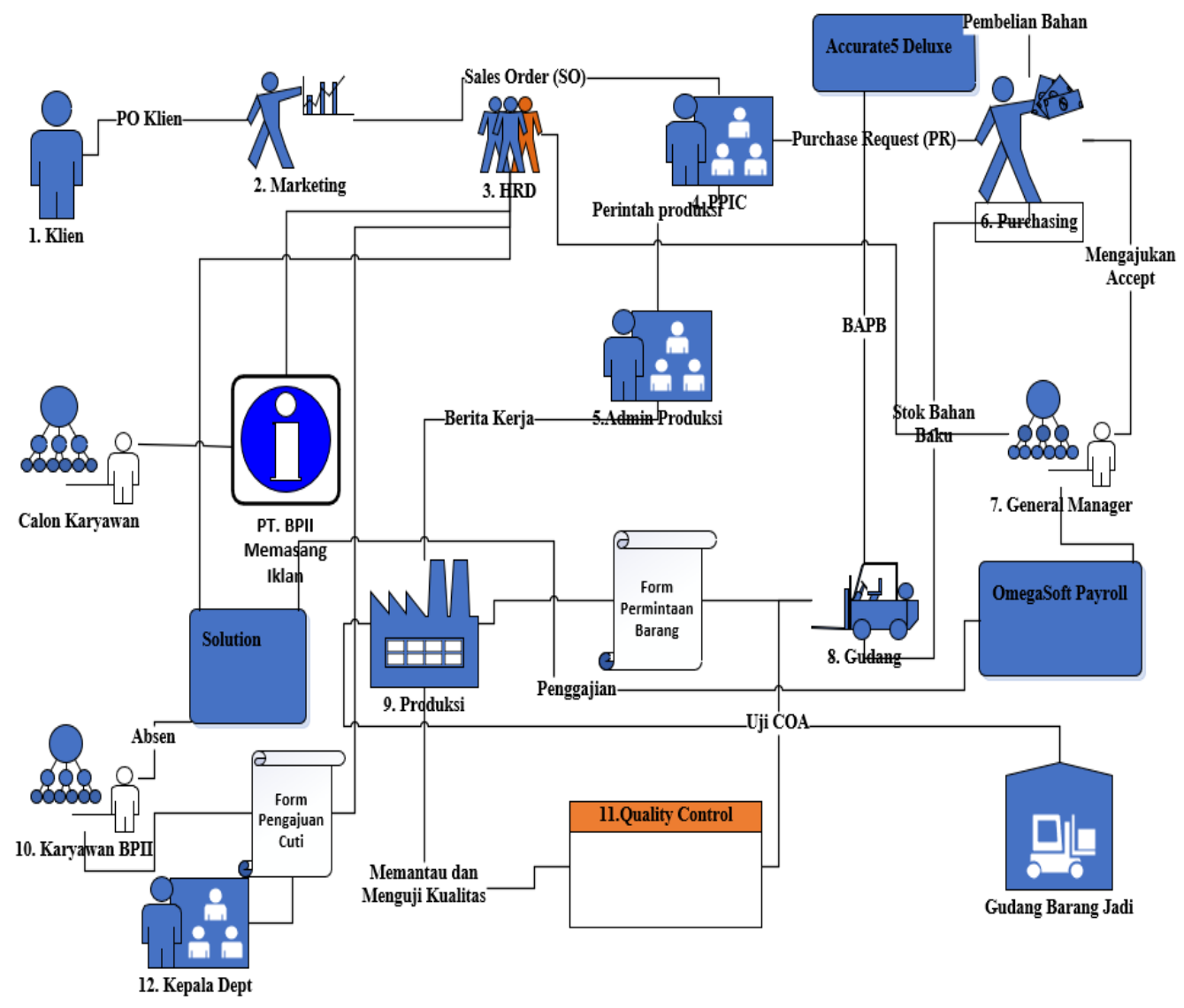

Gambar 5. Desain Arsitektur Bisnis Saat Ini

Berdasarkan Gambar Desain Arsitektur Bisnis Saat Ini dijelaskan, dimulai dari (1) terdapat klien yang mengajukan Purchase Order (PO) ke bagian (2) Marketing PT. BPII. Disini klien akan mendapat sampel produk dari marketing, marketing mengajukan estimasi dan penawaran harga produksi. Lalu, (4) PPIC mendapat Sales Order (SO) dari marketing. Pihak PPIC mempelajari bahan baku dan waktu yang dibutuhkan untuk produksi, jika bahan baku tidak ada PPIC membuat Purchase Request (PR) ke bagian (6) Purchasing. Purchasing membuat Purchase Order (PO) melalui Accurate lalu dicetak, kemudia dilihat oleh (7) General Manager. Setelah PO telah disetujui, bagian Purchasing melakukan order bahan baku dan memberi info kebagian (8) Gudang untuk mempersiapkan BAPB (Berita Acara Penerimaan Barang) melalui Accurate. Lalu, dari (4) PPIC diteruskan ke bagian (5) Admin Produksi untuk perintah produksi dilanjutkan berita kerja kebagian (9) produksi. Kinerja produksi akan dipantau dan hasil produksinya akan diuji secara teratur oleh bagian (11) Quality Control, namun jika bagian produksi membutuhkan bahan baku atau bahan penolong harus mengajukan form permintaan barang ke bagian Gudang. Stok bahan baku maupun penolong yang akan habis bagian Gudang mengajukan form Purchase Request kebagian Purchasing. Bahan baku yang datang untuk proses produksi akan diuji COA oleh bagian Quality Control, lalu hasil produksi yang sudah selesai dan diperiksa oleh Quality Control dan ditempatkan di gudang barang jadi dan siap dikirim ke klien.

Karyawan PT. BPII yang ingin mengajukan cuti harus mengisi form pengajuan cuti, meminta ACC atau approved oleh Kepala Dept dan General Manager melalui (3) HRD. Untuk pencarian karyawan PT. BPII membuat iklan yang disebarkan kepada calon karyawan atau pelamar. Untuk proses penggajian karyawan melalui Solution yang di proses dahulu oleh bagian (3) HRD , lalu diteruskan ke Omega yang penggunaannya dikendalikan oleh (7) General Manager. 
Selanjutnya, desain arsitektur model bisnis berikut ini akan dipadukan dengan aplikasi yang akan diusulkan:

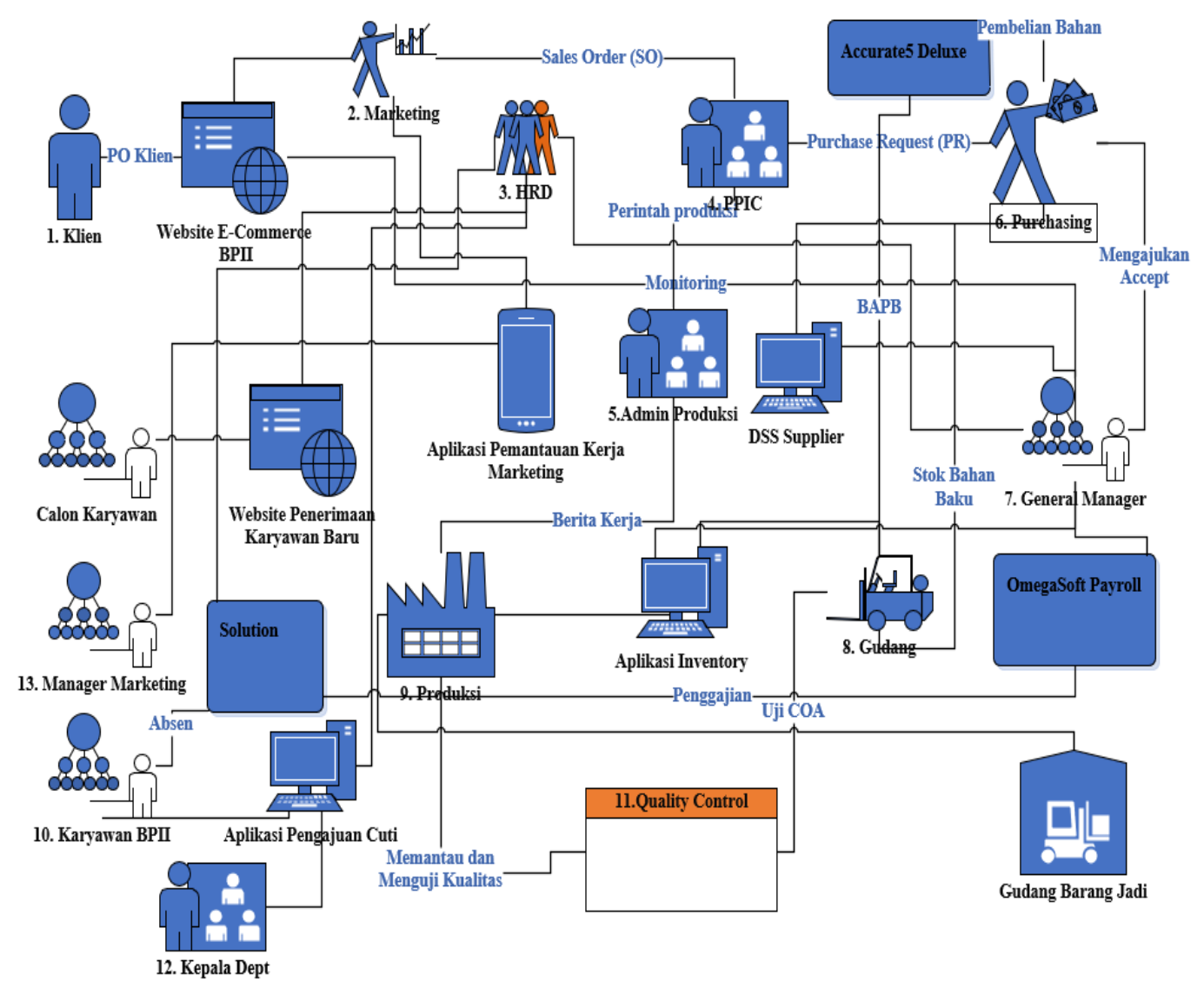

Gambar 6. Blue Print Desain Arsitektur Bisnis Yang Diusulkan

Berdasarkan Gambar 6. Blue Print Desain Arsitektur Bisnis Yang Diusulkan telah dipadukan dengan aplikasi usulan, berikut penjelasan:

a. DSS Produsen, membantu PT. BPII dalam menentukan supplier untuk bahan baku maupun bahan penolong.

b. Website E-Commerce, dengan mengembangkan website perusahaan agar mampu menjadi media penghubung antara klien dengan PT. BPII melalui marketing

c. Website untuk penerimaan karyawan baru, membantu perusahaan mencari calon karyawan (pelamar kerja).

d. Aplikasi inventory, membuat proses permintaan barang (bahan) dari bagian produksi kebagian Gudang menjadi efisien.

e. Aplikasi Monitoring Sales, memantau lokasi dan kinerja dari sales PT. BPII saat diluar perusahaan.

f. Aplikasi Pengajuan Cuti, membuat proses pengajuan cuti karyawan lebih efisien.

\section{KESIMPULAN}

Dari hasil pembahasan diskusi di atas, kesimpulan dalam penelitian ini sebagai berikut :

Sebelumnya, proses bisnis PT. BPII sudah menerapkan teknologi informasi namun karena penggunaan teknologi itu belum maksimal dalam membantu aktivitas bisnis perusahaan. Sehingga dalam penulisan ini dirancang arsitektur bisnis, untuk mengembangkan antara teknologi informasi dengan proses bisnis yang selaras dengan visi PT. BPII. Dengan didukung dengan penggunaan 
framework TOGAF, yang menghasilkan sebuah hasil berupa cetak biru (blueprint). Blueprint yang dihasilkan diharapkan bisa membantu perusahaan untuk lebih maksimal dalam menjalankan proses bisnis, yang berpengaruh kepada kinerja dari karyawan agar lebih optimal dan efisien. Dengan begitu perusahaan dapat memberikan peningkatan terhadap kepuasan klien terkait hasil produksi, sehingga meningkatakan daya saing bisnis PT. BPII.

\section{UCAPAN TERIMA KASIH}

Terima kasih kepada Bapak Hendra sebagai Purchasing, Ibu Dies sebagai HRD, dan Ibu Susi sebagai General Manager dari PT. Bumi Poly Imas Industries (BPII) yang sudah meluangkan waktu beliau untuk membantu dalam proses pengumpulan data.

\section{DAFTAR PUSTAKA}

[1] M.- Mei Mei and J. F. Andry, "The Alignment of Business Process In Event Organizer And Enterprise Architecture Using TOGAF," JUTI J. Ilm. Teknol. Inf., vol. 17, no. 1, p. 21, 2019, doi: 10.12962/j24068535.v17i1.a734.

[2] S. Suryadi and J. Fernandes Andry, "Perancangan Enterprise Architecture Mengunakan Togaf Architecture Development Method (Studi Kasus: Yakuza Gym Jakarta Barat)," vol. 2, no. 2502, pp. 129-134, 2017.

[3] Anus Wuryanto, "Integrasi Sistem Informasi Dan Teknologi Informasi Melalui Metode Enterprise Architecture Planning pada," J. Ilmu Pengetah. Dan Teknol. Komput., vol. 3, no. 2, pp. 151-158, 2018.

[4] D. Irmayanti and B. Permana, "Perencanaan Arsitektur Enterprise Sistem Informasi Disnakersostrans Kabupaten Purwakarta Menggunakan TOGAF," J. Teknol. Rekayasa, vol. 3, no. 1, p. 17, 2018, doi: 10.31544/jtera.v3.i1.2018.17-28.

[5] R. Anggrainingsih, A. Aziz, U. Salamah, and S. Widya Sihwi, "Penyusunan Arsitektur Visi dan Arsitektur Bisnis Sebagai Tahapan Perancangan Arsitektur Enterprise Universitas Sebelas Maret (UNS) Dengan Framework TOGAF," J. Teknol. Inf. ITSmart, vol. 2, no. 2, p. 13, 2016, doi: 10.20961/its.v2i2.626.

[6] D. Rahmayanti, R. Andreswari, and R. Hanafi, "Analisis Dan Perancangan Enterprise Architecture Direktorat Metrologi Pada Menggunakan Framework Togaf Adm Analysis and Design of Enterprise Architecture in Directorate of Metrology on Personnel and Financial Function," vol. 6, no. 2, pp. 106-114, 2019.

[7] Y. M. Geasela dan J. F. Andry, "Design Enterprise Architecture In Cpo Industry Using Togaf Adm Design Enterprise Architecture In Cpo Industry Using Togaf Adm Framework, ICTACT Journal On Soft Computing, October 2019, Volume: 10, Issue: 01, pp. 2022-2027, 2019, doi: 10.21917/ijsc.2019.0286.

[8] S. Entas, "Perancangan Arsitektur Enterprise Untuk Perguruan Tinggi Swasta Menggunakan TOGAF ADM (Studi Kasus STP Sahid Jakarta),” Paradigma, vol. XVIII, no. 1, pp. 67-78, 2016.

[9] R. Rismayati, "Ijns.Org,” Indones. J. Netw. Secur., vol. 5, no. 2, pp. 26-32, 2016.

[10] R. Yunis, "Arsitektur Bisnis : Pemodelan Proses Bisnis Dengan Object Oriented," Seminar, vol. 2010, no. semnasIF, pp. 167-173, 2010.

[11] L. Aryani and S. Assegaff, "Perencanaan Arsitektur Sistem Informasi Pada Kantor Kesehatan Pelabuhan Jambi Menggunakan Togaf Adm,”Jurnalmsi, vol. 2, no. 2, p. 429, 2017. 


\section{BIOGRAFI PENULIS}

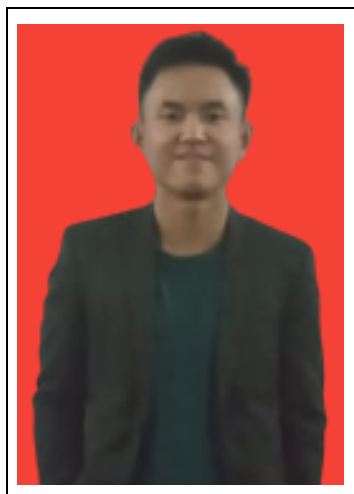

Brahmatia Wicaksono Lahir di Semarang tanggal 11 Mei 1998. Pendidikan Sekolah Dasar hingga SMA diselesaikan di DKI Jakarta. Menjadi mahasiswa aktif dari program studi sistem informasi di Universitas Bunda Mulia, Jakarta pada tahun 2016, saat ini sudah mencapai di semester akhir dan telah mengikuti sidang skripsi.

Johanes Fernandes Andry menyelesaikan pendidikan Ilmu Komputer di Universitas Budi Luhur, Jakarta. Sekarang aktif mengajar di Universitas Bunda Mulia Jakarta. Saat ini tertarik pada riset di bidang sistem informasi, pada area Audit Sistem Informasi, Software Enggineering dan Enterprise Architecture. Informasi tambahan ID Google Scholar: u71xmroAAAAJ, Scopus ID: 57203284629, Orcid ID: 0000-0003-0860-8953 dan ResearchGate: Johanes Andry. Menjadi reviewer di Jurnal Sistem Informasi Bisnis, Program Magister Sistem Informasi, Sekolah Pascasarjana Universitas Diponegoro, International Journal for Quality Research (indexing by scopus) dan The Walailak Journal of Science and Technology, Institute of Research and Innovation, Walailak University, Thasala, Nakhon Si Thammarat 80161, Thailand (indexing by scopus). 